\title{
Rancang Bangun Prototype Pengontrolan Lampu Gedung STMIK Amik Riau Berbasis IoT Menggunakan Rasberry Pi 3 Model B
}

\author{
Rometdo Muzawi ${ }^{1}$, Wahyu Joni Kurniawan ${ }^{2}$ \\ ${ }^{1}$ Prodi Manajemen Informatika STMIK Amik Riau, Pekanbaru \\ ${ }^{2}$ Prodi Sistem Informasi STIKOM Pelita Indonesia, Pekanbaru \\ rometdomuzawi@stmik-amik-riau.ac.id, wahyu.jonikurniawan@lecturer.pelitaindonesia.ac.id
}

\begin{abstract}
Internet of Things (IoT) is a hardware (Raspberry Pi) that can connect to the internet with the aim to expand the internet network that is connected thoroughly to the hardware. The development of the Internet of things (IoT) has been widely used, especially in this day and age, one of the utilization of this IoT technology is the control of electronic room light equipment through global network controlled via smartphone that can be operated remotely. This research aims to build a remote-control device by utilizing internet technology to perform the process of controlling the lights based on the Internet of Things (IoT). This research is done by building a prototype with mobile based application using python and php programming language. In this research there is a feature of controlling the room lights with the first condition of control of one lamp used to turn one room light and the second condition is used to turn the lights simultaneously.
\end{abstract}

Keywords - IoT, Raspberry Pi, Mobile, Prototype

\begin{abstract}
Abstrak
Internet of Things (IoT) merupakan sebuah perangkat keras (Raspberry Pi) yang dapat tersambung dengan internet dengan tujuan untuk memperluas jaringan internet yang terhubung secara menyeluruh pada hardware. Perkembangan Internet of things (IoT) telah banyak digunakan terutama pada zaman sekarang ini, salah satu dimanfaatkannya teknologi IoT ini adalah pengendalian peralatan elektronik lampu ruangan melalui jaringan internet global yang dikontrol melalui smartphone yang dapat dioperasikan dari jarak jauh. Penelitian ini bertujuan untuk membangun perangkat remote-control dengan memanfaatkan teknologi internet untuk melakukan proses pengendalian lampu berbasis Internet of Things (IoT) . Penelitian ini dilakukan dengan membangun sebuah prototype dengan aplikasi berbasis mobile menggunakan bahasa pemrograman python dan php. Dalam penelitian ini terdapat fitur pengendalian lampu ruangan dengan kondisi pertama kendali satu lampu yang digunakan untuk menghidupkan satu lampu ruangan dan kondisi kedua digunakan untuk menghidupkan lampu secara bersamaan.
\end{abstract}

Kata kunci-IoT, Raspberry Pi, Mobile, Prototype 


\section{PENDAHULUAN}

nternet of Things (IoT) merupakan sebuah perangkat keras (Raspberry Pi) yang dapat

$I$ tersambung dengan internet dengan tujuan untuk memperluas jaringan internet yang terhubung secara menyeluruh pada hardware[1]. Internet of Things (IoT) bisa dimanfaatkan pada gedung untuk mengendalikan peralatan elektronik seperti lampu ruangan yang dapat dioperasikan dari jarak jauh melalui jaringan komputer, tidak dapat dipungkiri kemajuan teknologi yang sedemikian cepat harus bisa dimanfaatkan,dipelajari serta diterapkan dalam kehidupan sehari-hari. Contohnya adalah perkembangan teknologi yang bisa dimanfaatkan dari adanya koneksi internet ini bisa mengakses peralatan elektronik seperti lampu ruangan yang dapat dioperasikan dengan cara online melalui mobile. Sehingga, dapat memudahkan pengguna memantau ataupun mengendalikan lampu kapanpun dan dimanapun dengan catatan di lokasi yang akan diterapkan teknologi kendali jarak jauh mempunyai jaringan internet yang memadai. Sistem kendali jarak jauh, memudahkan pengguna dalam mengontrol lampu gedung yang jaraknya cukup jauh lokasinya. Sementara pada penelitian yang lain "Purwa Rupa Internet of Things ( IoT ) Kendali Lampu Gedung " Teknologi sistem kendali ini dilakukannya dari sebuah komputer saja yang didalamnya terdapat sebuah sistem atau fitur software yang telah dibangun dan dirancang untuk melakukan tugas kendali tersebut terhadap lampu ruangan[2]. Dalam pengembangan dan perbaikan terhadap permasalahan diatas, maka pada penelitian ini peneliti menggunakan Rasberry Pi 3 . Rasberry Pi adalah salah satu komponen Internet of Things (IoT) yang dapat diaplikasikan sebagai pengendali jarak jauh dengan jaringan internet yang dapat diterapkan pada peralatan elektronik seperti lampu. Perangkat tersebut dapat diakses dengan layanan internet melalui smartphone android dengan Internet Protocol sehingga tingkat efisiensi tenaga dan waktu jam kerja petugas serta dari segi penghematan energi listrik yang digunakan. Teknologi ini tepat untuk diterapkan karena untuk memudahkan petugas dalam melakukan pekerjaan tersebut. Berdasarkan uraian di atas, maka peneliti bermaksud untuk melakukan penelitian untuk merancang prototype dan membuat program aplikasi mobile dan python menggunakan Rasberry Pi 3 sebagai pengendali lampu jarak jauh dengan jaringan internet yang dapat diterapkan pada peralatan elektronik seperti lampu sehingga tingkat efisiensi tenaga dan waktu jam kerja petugas serta dari segi penghematan energi listrik yang digunakan.

\subsection{Internet of Things atau}

Dikenal juga dengan singkatan IoT, merupakan sebuah konsep yang bertujuan untuk memperluas manfaat dari konektivitas internet yang tersambung secara terus- menerus yang memungkinkan kita untuk menghubungkan mesin, peralatan, dan benda fisik lainnya dengan sensor jaringan dan aktuator untuk memperoleh data dan mengelola kinerjanya sendiri, sehingga memungkinkan mesin untuk berkolaborasi dan bahkan bertindak berdasarkan informasi baru yang diperoleh secara independen [3]. Internet Of Things atau sering disebut IoT adalah sebuah gagasan dimana semua benda di dunia nyata dapat berkomunikasi satu dengan yang lain sebagai bagian dari satu kesatuan sistem terpadu menggunakan jaringan internet sebagai penghubung. misalnya CCTV yang terpasang di sepanjang jalan dihubungkan dengan koneksi internet dan disatukan di rung kontrol yang jaraknya mungkin puluhan kilometer. atau sebuah rumah cerdas yang dapat dimanage lewat smartphone dengan bantuan koneksi internet. pada dasarnya perangkat IoT terdiri dari sensor sebagai media pengumpul data,sambungan internet sebagai media komuniakasi dan server sebagai pengumpul informasi yang diterima sensor dan untuk analisa. Ide awal Internet of Things pertama kali dimunculkan oleh Kevin Ashton pada tahun 1999 di salah satu presentasinya [4]. Kini banyak perusahaan besar mulai mendalami Internet of Things sebut saja Intel, Microsoft, Oracle, dan banyak lainnya. Banyak yang memprediksi bahwa pengaruh Internet of Things adalah " the next big thing " di dunia teknologi informasi, hal ini karena IoT menawarkan banyak potensi yang bisa 
digali. Contoh sederhana manfaat dan implementasi dari Internet of Things misalnya adalah kulkas yang dapat memberitahukan kepada pemiliknya via SMS atau email tentang makanan dan minuman apa saja yang sudah habis dan harus distok lagi.

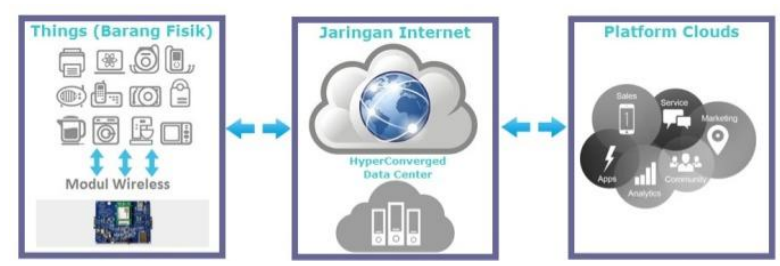

Gambar 1. Konsep IOT

\subsection{Raspberry Pi}

Raspberry Pi adalah suatu perangkat mini computer berukuran sebesar kartu kredit. Raspberry Pi memiliki sistem Broadcom BCM2835 chip (SoC), yang mencakup ARM1176JZF-S $700 \mathrm{MHz}$ processor (firmware termasuk sejumlah mode "Turbo" sehingga pengguna dapat mencoba overclocking, hingga $1 \mathrm{GHz}$ ), VideoCore IV GPU, dan awalnya dikirim dengan 256 megabyte RAM, kemudian upgrade ke 512MB. Termasuk built-in hard disk atau solid-state drive, tetapi menggunakan kartu SD untuk booting dan penyimpanan jangka panjang [5].

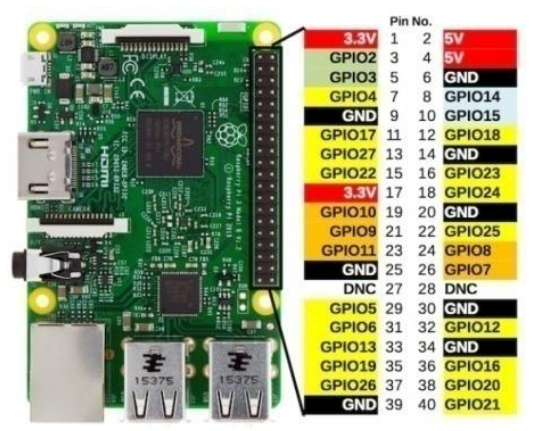

Gambar 2. Raspberry Pi

\subsection{Penelitian Terdahulu}

[2]Penelitian yang dilakukan oleh Kurniawan adalah IoT (Internet of Things) Kendali Lampu Gedung. Permasalahan yang melatari penelitian ini adalah sistem kendali lampu ini masih dilakukan secara manual,sehingga pengguna mengalami kesulitan dalam memantau atau mengendalikan. Penelitian ini menggunakan $\mathrm{n}$ model proses pengembangan prototype. Proses penelitian ini dimulai analisa, perancangan prototype, analisa program, dan pengujian prototype. Aplikasi ini dibuat menggunakan bahasa pemrograman java dengan database mysql.

[5]Penelitian yang dilakukan oleh Malik Abdillah Ibnul Hakim dan Yeffry Handoko Putra adalah pemanfaatan mini pc raspberry pi sebagai pengontrolan jarak jauh berbasis web pada rumah. Permasalahan yang melatari penelitian ini adalah proses yang sedang berjalan masih dilakukan manual dalam pengontorlan lampu.. Sedangkan tujuan penelitian ini adalah membuat aplikasi berbasis web yang dapat melakukan pengontorlan lampu. Proses penelitian ini dimulai dari analisis kebutuhan, analisa rancangan sistem,analisa program dan pengujian aplikasi web. 


\section{METODE PENELITIAN}

Tahapan-tahapan penelitian yang digunakan dalam metode ini sebanyak 4 tahapan yang digambarkan berikut ini:

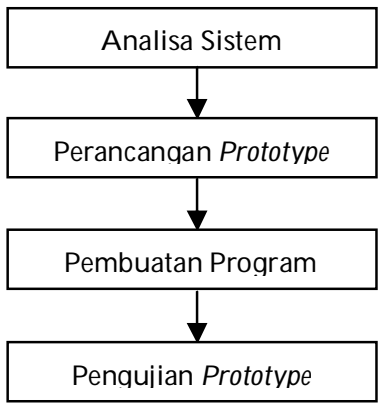

\section{Analisa Sistem}

Gambar 3. Alur Kerangka Kerja Penelitian

Analisis kebutuhan sistem ini ditujukan untuk menguraikan kebutuhan-kebutuhan yang harusdisediakan oleh sistem agar dapat memenuhi kebutuhan pengguna dan sesuai dengan tujuan penelitian yaitu melakukan perancangan rancang bangun pengontrolan lampu berbasis internet of things menggunakan raspberry pi. Rancangan sistem ini menjelaskan kebutuhan antarmuka, kebutuhan data masukan dan data keluaran yang menunjukkan spesifikasi sistem yang dapat diakses.

\section{Analisa Fungsional}

Analisa Kebutuhan fungsional merupakan gambaran mengenai fungsi-fungsi yang dapat dilakukan oleh sistem ini. Kebutuhan fungsional sistem meliputi:

a. Sistem yang dirancang berbasis mobile.

b. pada sistem mobile harus terinstal di smartphone.

c. Adanya fasilitas mematikan lampu per ruangan dan keseluruhan lampu secara bersamaan.

\section{Analisa Non Fungsional}

Analisa Kebutuhan non-fungsional adalah kebutuhan sistem meliputi kinerja, kelengkapan operasi pada fungsi-fungsi yang ada, serta kesesuaian dengan lingkungan penggunanya. Kebutuhan nonfungsional ini melingkupi beberapa kebutuhan yang mendukung kebutuhan fungsional, rumusan kebutuhan non-fungsional meliputi:

a. Kebutuhan Operasional

1. Pada sistem mobile, wajib terkoneksi internet.

2. Pada sistem mobile, aplikasi dapat terinstal pada perangkat Android.

3. Pada sistem mobile, sistem hanya dapat diakses melalui file format.apk yang telah terinstal di perangkat Android.

4. User interface pada aplikasi dibuat dengan sederhana untuk memudahkan pengguna.

b. Performance sistem sistem yang dibangun merupakan aplikasi yang berjalan pada lingkungan perangkat bergerak. Terdapat beberapa keterbatasan yang ditemui pada perangkat. Oleh karena itu perlu diperhatikan guna menjadi acuan dalam pengembangan sistem, diantaranya:

1. Sumber daya listrik digunakan se efektif mungkin.

2. Tampilan aplikasi antarmuka disesuaikan dengan kebutuhan.

3. Merancang aplikasi dengan antarmuka yang sederhana namun tetap menarik dan mudah digunakan oleh pengguna. 


\section{Perancangan Protoype}

Dalam membuat rancangan prototype sesuai data yang ada berdasarkan tahapan yang ditetapkan pada tahapan analisa data. Diperlukan rancangan sistem pengendalian lampu berbasis mobile.

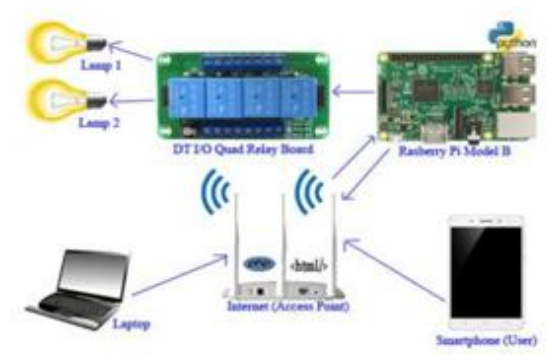

Gambar 4. Rancangan Prototype Sistem

\section{Pembuatan Program}

Membuat sebuah aplikasi dengan berbasiskan Rasberry Pi 3 dalam pengedalian lampu berbasis Mobile.

\section{Pengujian Prototype}

Menguji seluruh spesifikasi terstruktur dan aplikasi secara keseluruhan. Pada tahap ini dilakukan uji coba aplikasi yang telah selesai dibuat. Proses uji coba ini diperlukan untuk memastikan bahwa aplikasi yang telah dibuat sudah benar, sesuai dengan karakteristik yang ditetapkan dan tidak ada kesalahan yang terkandung didalamnya.

\section{HASIL DAN PEMBAHASAN}

Dari point 4 diatas perancangan rancang bangun pengontrolan lampu berbasis internet of things dimulai pemakain DT Relay seperti gambar berikut:

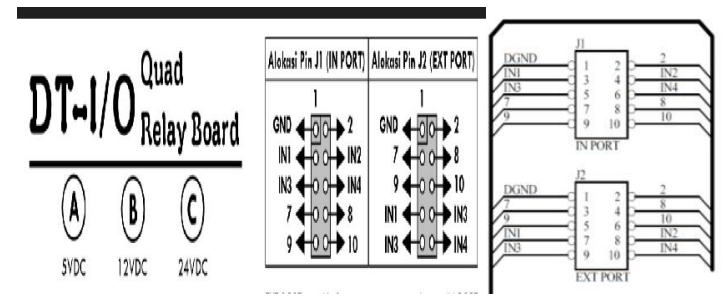

Gambar 5. Datasheet DT-I/O Quad Relay Board

Setelah DT- Relay, dilanjutkan mengatur Data Sheet Raspberry Pi 3 dengan tampilan seperti gambar berikut: 


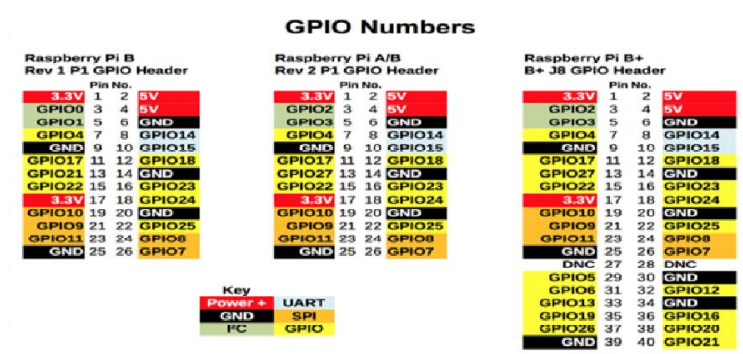

Gambar 6. Datasheet GPIO Numbers Raspberry Pi 3

Maka akan tampil, koneksi prototype DT-Relay dengan Raspeberry Pi 3 yang terhubung dengan menggunakan kabel pelangi. Tampilan sebagai berikut :
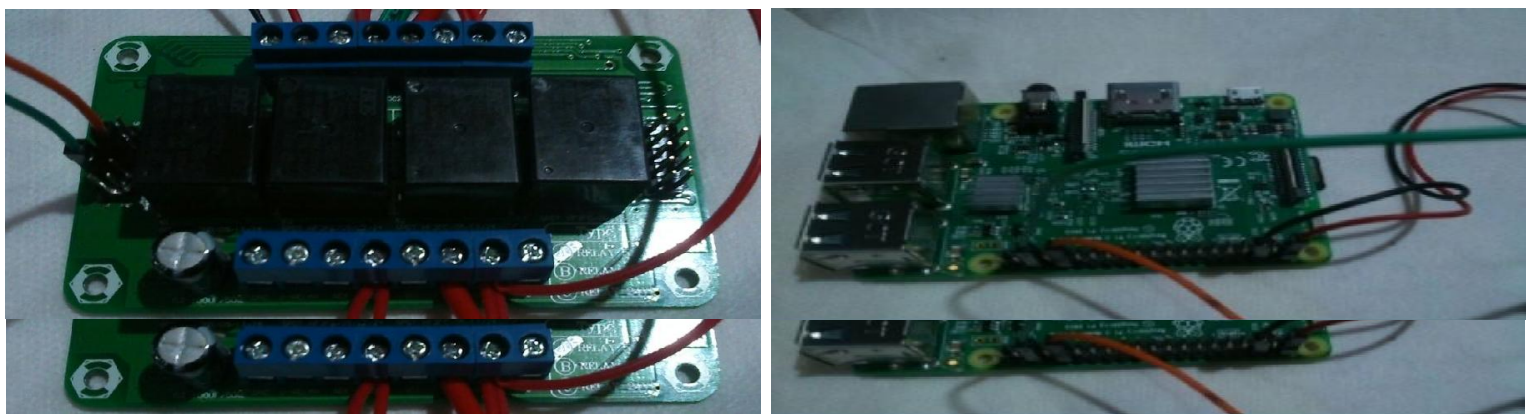

Gambar 7. Rangkaian DT-I/O Quad Relay Board dan Raspberry Pi 3

Setelah koneksi DT-Relay dan Raspberry Pi 3 terkoneksi lalu persiapkan 2 fitting lampu dengan bola lampu. Untuk tampilan lebih baik bisa kita gunakan akrilik untuk membatasi antara ruang lampu yang satu dengan yang lainnya. Dapat dilihat pada gambar berikut:

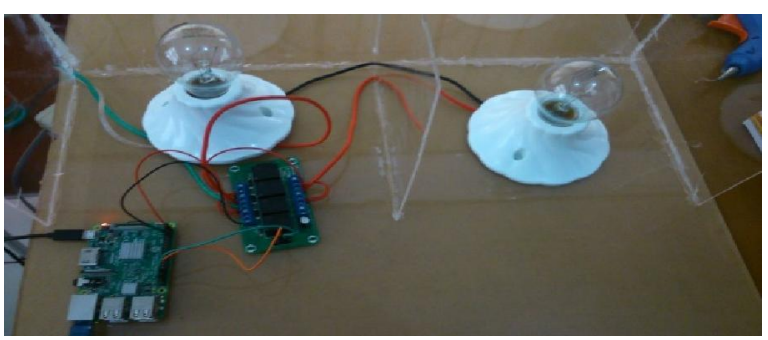

Gambar 8. Prototype Kendali Lampu

\section{Pembuatan Program}

Dalam pembuatan program pengontrolan lampu berbasis internet of things peneliti menggunakan bahasa pemrograman python dan mobile, berikut tampilan pemrograman python nya: 


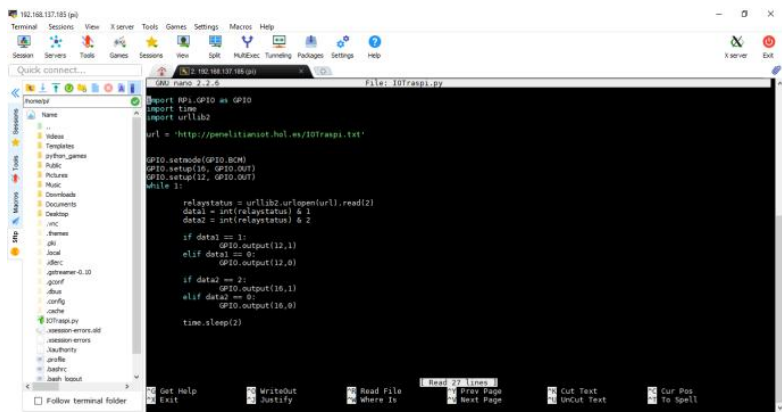

Gambar 9. Script Python

\section{Hasil Pengujian Implementasi}

Pada aplikasi ini dapat menampilkan infromasi pengedalian lampu yang nantinya akan dilihat dan dicek langsung oleh petugas menggunakan aplikasi mobile. Berikut ini tampilan aplikasi pengendalian lampu:

1. Tampilan mobile posisi lampu mati semua
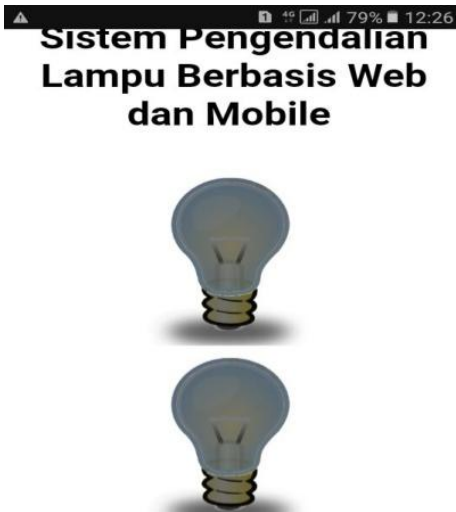

Gambar 10. Tampilan Mobile Posisi Lampu Mati Semua

2. Tampilan mobile posisi 1 bola lampu menyala
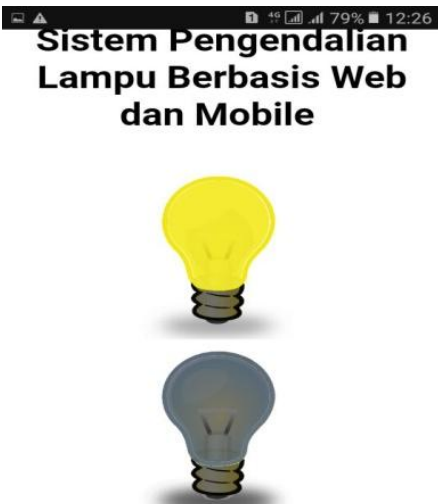

Gambar 11. Tampilan Mobile Posisi 1 Bola Lampu Menyala 
3. Tampilan mobile posisi bola lampu ke 2 menyala

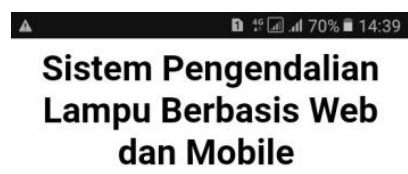

Gambar 12. Tampilan Mobile Posisi Bola Lampu ke 2 Menyala

\section{Hasil Pengujian}

Berdasarkan hasil pengujian prototype kendali lampu testing yang dilakukan terhadap fungsi dan kinerja setiap dari aplikasi mobile berjalan dengan baik, dapat diketahui bahwa aplikasi pengontrolan lampu ini berjalan sesuai dengan kondisi yang di tanam pada sistem raspberry pi penjualan, dimana konidis pertama lampu dalam penelitian ini terdapat fitur pengendalian lampu ruangan dengan kondisi pertama kendali lampu satu yang digunakan untuk menghidupkan satu lampu ruangan dan kondisi kedua digunakan untuk menghidupkan lampu secara bersamaan.

\section{KESIMPULAN}

Berdasarkan hasil pengujian prototype kendali lampu testing yang dilakukan maka dapat disimpulkan bahwa aplikasi ini telah memenuhi atau telah sesuai dengan kebutuhan capaian dari peneliti. Selain itu, aplikasi ini juga dapat meningkatkan kinerja dan efisiensi waktu dalam pengontrolan lampu dari jauh, sehingga dapat membantu pengguna.

\section{UCAPAN TERIMA KASIH}

Penulis mengucapkan terima kasih kepada Kemenristekdikti (Koperti Wilayah X) yang telah mendukung dan mendanai Penelitian Dosen Pemula Tahun 2018 Nomor Kontrak: 0033/K10/KM/2018 dan terima kasih juga kepadaLPPM STMIK Amik Riau yang telah memfasilitasi sehingga penelitian ini dapat terlaksana dengan baik.

\section{DAFTAR PUSTAKA}

[1] W. A. Muzawi, Rometdo, Yoyon Efendi, "SATIN - Sains dan Teknologi Informasi Sistem Pengendalian Lampu Berbasis Web dan Mobile," SATIN - Sains dan Teknol. Inf., vol. 4, no. 1, 2018. 
[2] Kurniawan, "Purwarupa IoT (Internet of Things) Kendali Lampu Gedung (Studi Kasus Pada Gedung Perpustakaan Universitas Lampung)," vol. 57, 2016.

[3] U. N. K. Yuliza, "Robot Pembersih Lantai Berbasis Arduino Uno Dengan Sensor Ultrasonik," J. Teknol. Elektro, Univ. Mercu Buana, vol. 6, no. 3, pp. 136-143, 2015.

[4] E. D. Meutia, "Internet of Things - Keamanan dan Privasi," Semin. Nas. dan Expo Tek. Elektro 2015, pp. 85-89, 2015.

[5] M. A. I. Hakim and Y. H. Putra, "Pemanfaatan Mini Pc Raspberry Pi Sebagai Pengontrol Jarak Jauh Berbasis Web Pada Rumah. Unikom,” pp. 1-6, 2013. 